\title{
RANCANG BANGUN APLIKASI REKOMENDASI AKOMODASI DAN INFORMASI PARIWISATA BERBASIS ANDROID DI KOTA PEKANBARU
}

\author{
Rama Putra ${ }^{1}$, Afdhil Hafid ${ }^{2}$, Edo Arribe ${ }^{3}$, Harun Mukhtar ${ }^{4}$ \\ ${ }^{14}$ Teknik Informatika, Fakultas Ilmu Komputer, Universitas Muhammdiyah Riau \\ ${ }^{2}$ Sistem Informasi, Fakultas Sains dan Teknologi, Universitas Islam Negeri Imam Bonjol Padang \\ ${ }^{3}$ Sistem Informasi, Fakultas Ilmu Komputer, Universitas Muhammdiyah Riau \\ email: ${ }^{1}$ ramaputra@student.umri.ac.id, ${ }^{2}$ afdhilhafid@umri.ac.id, ${ }^{3}$ edoarribe@umri.ac.id, \\ harunmukhtar@umri.ac.id
}

\begin{abstract}
Pekanbaru City is the capital of Riau Province which has considerable tourism potential. In addition, the number of accommodation and occupancy rates of tourists in Pekanbaru City have the highest level in Riau Province. Tourists who come have a variety of purposes, namely entertainment, meetings, business and others. The many advantages possessed by the city of Pekanbaru cannot be separated from problems, namely the limited information technology that is owned by the city of Pekanbaru. To help the city of Pekanbaru in developing its existing potential, an android-based application was built that can recommend accommodation and offer tourism information around the accommodation. The results obtained from the implementation of this application are recommendations for accommodation around the user's destination and tourism information that exists around the accommodation, as well as a map of the direction to accommodation and tourism locations
\end{abstract}

Keywords: application, recommendations, accommodation, tourism, android

\begin{abstract}
Abstrak
Kota Pekanbaru merupakan ibukota Provinsi Riau yang memiliki potensi pariwisata yang cukup besar. Selain itu, jumlah akomodasi dan tingkat penghunian wisatawan di Kota Pekanbaru memiliki tingkat tertinggi di Provinsi Riau. Wisatawan yang datang mempunyai beragam tujuan yaitu hiburan, pertemuan, bisnis dan lain - lain. Banyaknya keunggulan yang dimiliki Kota Pekanbaru tidak lepas dari masalah, yaitu terbatasnya teknologi informasi yang yang dimiliki Kota Pekanbaru. Untuk membantu Kota Pekanbaru dalam mengembangkan potensi yang ada, dibangunlah aplikasi berbasis android yang dapat merekomendasikan akomodasi dan menawarkan informasi pariwisata yang ada disekitaran akomodasi tersebut. Hasil yang diperoleh dari implementasi aplikasi ini adalah rekomendasi akomodasi disekitaran lokasi tujuan pengguna dan informasi pariwisata yang ada disekitaran akomodasi tersebut, serta peta petunjuh arah ke lokasi akomodasi maupun pariwisata.
\end{abstract}

Kata kunci: aplikasi, rekomendasi, akomodasi, pariwisata, android

\section{PENDAHULUAN}

Kota Pekanbaru adalah ibukota dan kota terbesar di Provinsi Riau, Indonesia. Dinas Kebudayaan dan Pariwisata Kota Pekanbaru (2017) menyatakan Pekanbaru memiliki potensi yang sangat besar sebagai daerah tujuan pariwisata. Berada ditengah-tengah pulau Sumatera sehingga memudahkan siapa saja yang ingin berkunjung ke ibukota Riau ini. Dapat dilihat dari data tingkat penghunian akomodasi yang ditinjau pada Publikasi Badan Statistik Provinsi Riau tahun 2017, Kota Pekanbaru memiliki jumlah wisawatan terbanyak di Provinsi Riau[31]. Namun, banyaknya wisatawan yang datang ke Kota Pekanbaru bertujuan bukan hanya untuk melakukan aktifitas pariwisata. Wisatawan yang datang mempunyai beragam tujuan yaitu berlibur, bisnis, pertemuan, pendidikan, penelitian dan lain - lain.

Usaha akomodasi merupakan usaha yang menyediakan tempat penginapan jangka pendek untuk pengunjung dan pelancong lainnya. Ditinjau dari data Badan Pusat Statistik Provinsi Riau tahun 2016 yang dipublikasi pada tahun 2017, Pekanbaru merupakan urutan teratas dengan jumlah hotel dan akomodasi lainnya terbanyak di Provinsi Riau yaitu 108 
unit. Pada tahun 2018, data akomodasi di Kota Pekanbaru meningkat menjadi 138 unit[30].

Dengan tingginya tingkat hunian wisatawan dan pertumbuhan jumlah akomodasi, tentunya Kota Pekanbaru juga harus berbenah untuk mengembangkan potensi tersebut agar wisatawan lebih melihat aspek pariwisata di Kota Pekanbaru. Selain itu, banyaknya akomodasi yang tersedia di Kota Pekanbaru bukan tidak mungkin wisatawan bingung menentukan akomodasi sesuai dengan keinginannya. Dibutuhkan sebuah aplikasi yang merekomendasikan akomodasi sesuai dengan keinginan wisatawan yang menawarkan informasi pariwisata.

Sampai saat ini Kota Pekanbaru masih sangat minim dalam penyediaan sistem informasi dan rekomendasi mengenai tempat penginapan serta informasi pariwisata. Namun, informasi dan rekomendasi mengenai akomodasi yang ada di Kota Pekanbaru bisa ditemui di berbagai website, salah satunya pada website www.traveloka.com. Pada website ini tidak hanya memberikan informasi akomodasi di Kota Pekanbaru tetapi juga akomodasi seluruh Indonesia, sehingga tidak terlihat lebih spesifik hanya membahas akomodasi di Kota Pekanbaru. Selain itu, pada website tersebut tidak menyediakan informasi tempat pariwisata di sekitaran akomodasi yang lebih kompleks. Berdasarkan dari uraian tersebut penulis menganggap perlu adanya sebuah aplikasi rekomendasi akomodasi dan informasi pariwisata di Kota Pekanbaru berbasis android yang diharapkan dapat membantu dan mendukung Kota Pekanbaru dalam mengembangkan potensi pariwisata.

\section{METODE PENELITIAN}

Dalam menyusun penelitian ini maka ada beberapa metode serta prosedur yang penulis terapkan dalam tahap-tahap melakukan penelitian:

a. Menentukan kebutuhan penelitian dan pengumpulan data.

b. Menentukan metode pengembangan sistem. Pada aplikasi yang dibuat menggunakan model waterfall yaitu model yang menyediakan pendekatan alur hidup perangkat lunak secara sekuensial atau terurut dimulai dari tahap analisis, perancangan, implementasi, pengujian dan pendukung [14].

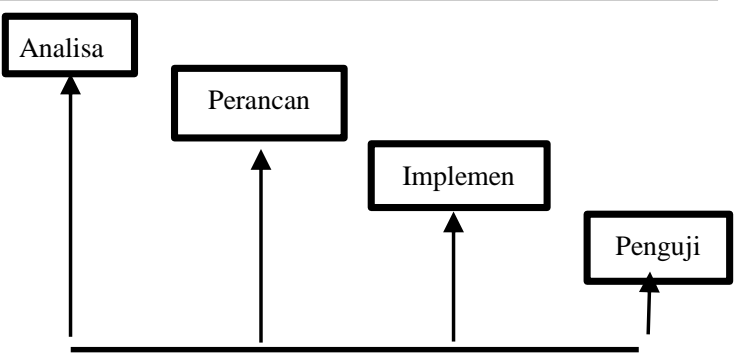

Gambar 1. Model Waterfall

\section{HASIL DAN PEMBAHASAN}

1. Analisa Sistem

Hasil dari analisa sistem yang bertujuan untuk menentukan kebutuhan-kebutuhan sistem yang terbagi dua jenis, yaitu kebutuhan fungsional dan kebutuhan non fungsional.

Tabel 1. Kebutuhan Fungsional

\begin{tabular}{|c|l|l|}
\hline No & \multicolumn{1}{|c|}{$\begin{array}{c}\text { Nama } \\
\text { Fungsi }\end{array}$} & \multicolumn{1}{|c|}{ Deskripsi } \\
\hline 1 & $\begin{array}{l}\text { Form Input } \\
\text { Parameter }\end{array}$ & $\begin{array}{l}\text { Fungsi yang merupakan } \\
\text { fasilitas bagi user untuk } \\
\text { memilih parameter sesuai } \\
\text { dengan keinginan. }\end{array}$ \\
\hline 2 & Pencarian & $\begin{array}{l}\text { Fungsi untuk memudahkan } \\
\text { user dalam mencari } \\
\text { akomodasi sesuai dengan } \\
\text { tujuannya. }\end{array}$ \\
\hline 3 & $\begin{array}{l}\text { Detail } \\
\text { Akomodasi }\end{array}$ & $\begin{array}{l}\text { Fungsi yang merupakan } \\
\text { fasilitas bagi user melihat } \\
\text { detail akomodasi. }\end{array}$ \\
\hline 4 & $\begin{array}{l}\text { Informasi } \\
\text { Pariwisata }\end{array}$ & $\begin{array}{l}\text { fasilitas bagi user untuk } \\
\text { melihat detail informasi } \\
\text { pariwisata. }\end{array}$ \\
\hline 5 & Map & $\begin{array}{l}\text { Fungsi yang merupakan } \\
\text { fasilitas bagi user untuk } \\
\text { melihat rute perjalanan dan } \\
\text { petunjuk arah. }\end{array}$ \\
\hline
\end{tabular}

Sedangkan kebutuhan non fungsional terbagi dua yaitu:

a. Kebutuhan Perangkat Keras (Hardware).

- 1 unit komputer lengkap dengan monitor.

- Spesifikasi komputer menggunakan prosesor Amd Phenom x4.

- Kebutuhan memori 2 GB - 4 GB RAM.

- Smartphone Sony Xperia Z5 android Nougat 7.1 untuk mencoba aplikasi.

b. Kebutuhan Perangkat Lunak (Software).

- Sistem operasi yang dapat digunakan yaitu Microsoft Windows 7 Ultimate..

- Android Studio Versi 3.1.3, digunakan untuk pembuatan desain aplikasi.

- Test localhost server dan sekaligus penyimpanan database menggunakan XАMPP v3.2.2 
- Microsoft Office Visio 2016 digunakan untuk desain perancangan system

- Aplikasi browser seperti Google Chrome versi 54.02840.68 dan Mozilla Firefox versi 53.0.2.

\section{Perancangan Sistem}

Perancangan sistem yang digunakan untuk mengembangkan aplikasi ini adalah Unified Modeling Language (UML).

Permodelan yang digunakan yakni use case diagram, actifity diagram, sequence diagram, dan class diagram lalu ditambah dengan perancangan tabel dari database aplikasi yang akan dibangun serta diagram relasi antar tabel dari database

a. Use Case Diagram

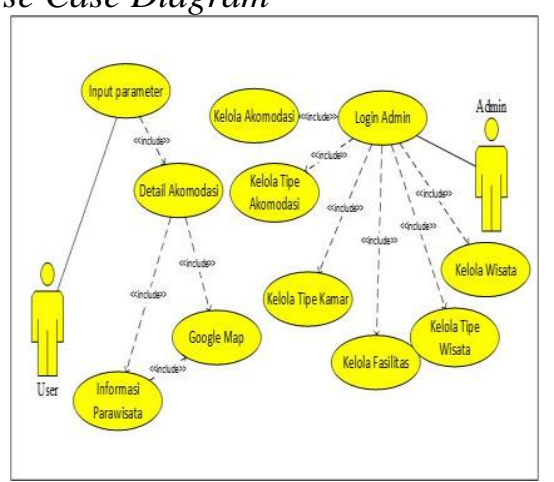

Gambar 2. Use Case Diagram

b. Actifity Diagram

Activity diagram digunakan untuk memberikan gambaran mengenai alur aktivitas di dalam use case diagram. Beberapa activity diagram penting dari sistem yang akan dibangun yaitu input parameter, detail akomodasi, informasi pariwisata, google map, login admin, kelola akomodasi, tipe akomodasi, tipe kamar, fasilitas, data pariwisata dan tipe pariwisata.

\section{c. Sequence Diagram}

Sequence diagram adalah tool yang sangat populer dalam pengembangan sistem informasi secara objectoriented untuk menampilkan interaksi antar objek. Berikut gambaran sequence diagram yang diusulkan untuk aplikasi rekomendasi hotel dan informasi pariwisata.

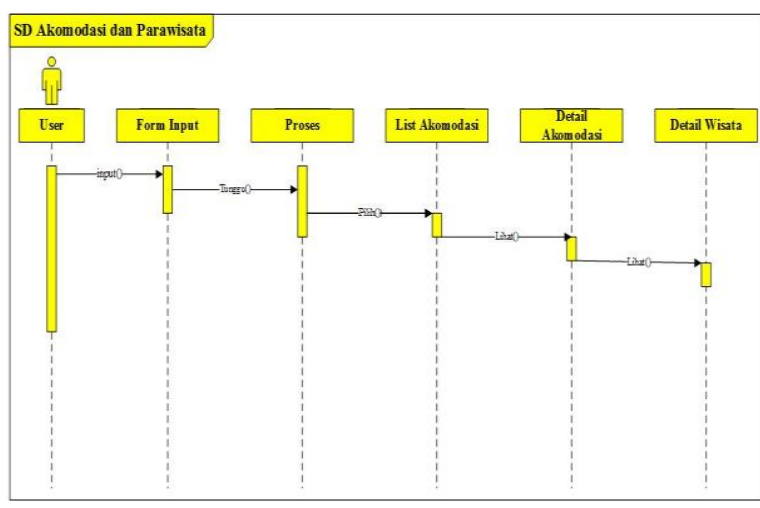

Gambar 3. Sequence Diagram

d. Class Diagram

Class Diagram menggambarkan keadaan (atribut/properti) sistem, sekaligus menawarkan layanan untuk memanipulasi keadaan tersebut (metoda/ fungsi). Adapun Class Diagram dari aplikasi ini adalah sebagai berikut:

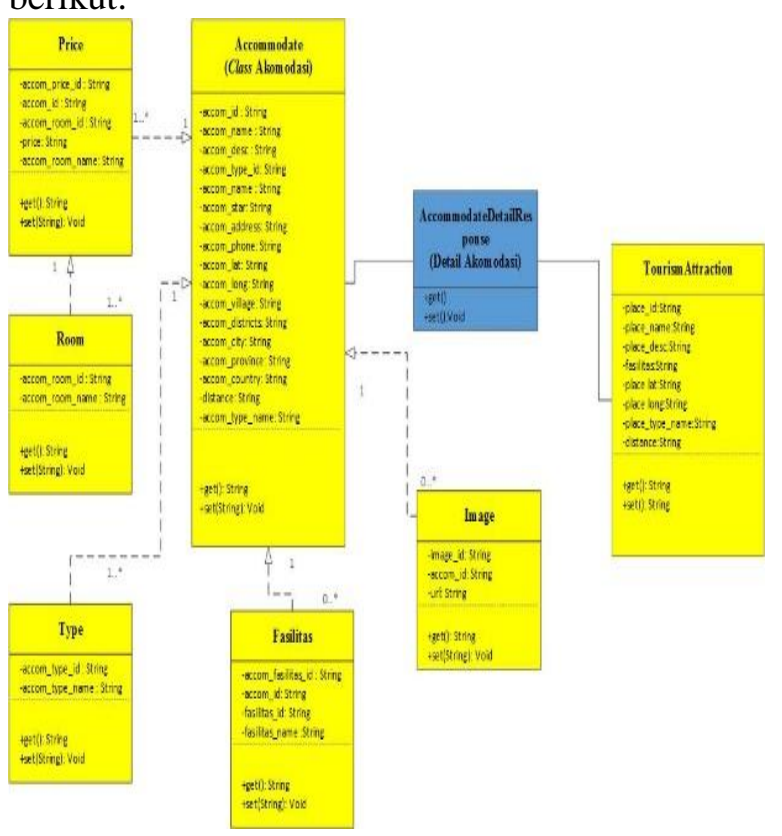

Gambar 4. Class Diagram

e. Perancangan Database

Implementasi dari perancangan database dari aplikasi dapat dilihat pada gambar 4. berikut: 


\begin{tabular}{|c|c|c|c|}
\hline TElle 。 & Adom & Plows of hipe Collowion & Sie Ge Geted \\
\hline [1 sounnebte & 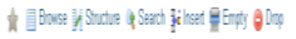 & 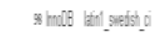 & siti \\
\hline 2 amonodte fasits & 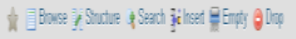 & 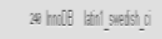 & sti \\
\hline [] rconnodte ingege & 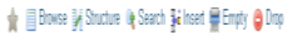 & 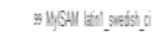 & 5.5 tia \\
\hline aconnodite pine & 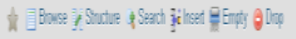 & 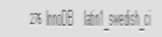 & sia \\
\hline [ rounnobte foum & 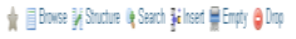 & 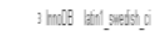 & sta \\
\hline ] rcounnobte tye & 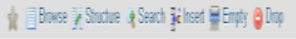 & 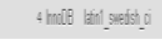 & sti \\
\hline [1] frilits & 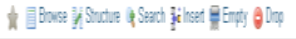 & 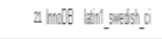 & stis \\
\hline Douss & 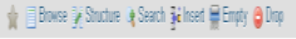 & 5 mib uf gesed i & S12 \\
\hline 0 login _tents & 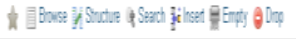 & itmolb uffereal i & sis \\
\hline [ twise atrodion & 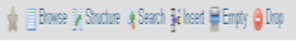 & II mald latil vests of & 512 \\
\hline 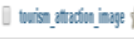 & 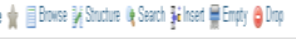 & 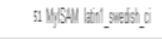 & 3812 \\
\hline Q twisis atrodion .jpe & 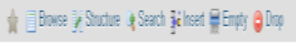 & I theld tat sefstio & 细 \\
\hline [1 & 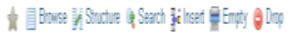 & 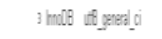 & stia \\
\hline wes grous & 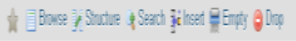 & imlB af gaed ai & Ali \\
\hline H tables & $\sin$ & 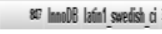 & 3B.36B \\
\hline
\end{tabular}

\section{HASIL DAN PEMBAHASAN}

a. Tampilan Menu Utama

Pada saat membuka aplikasi maka aplikasi akan menampilkan halaman menu utama. Pada halaman ini user dapat melakukan beberapa inputan parameter yaitu lokasi tujuan, tipe akomodasi, tipe kamar dan harga.

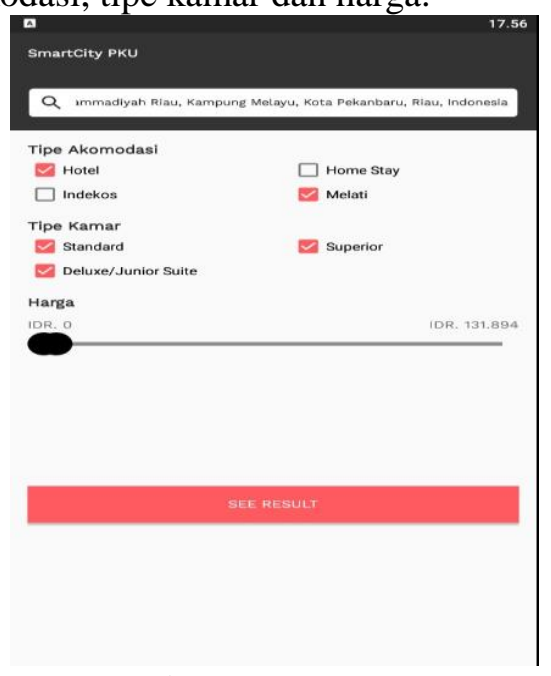

Gambar 6. Menu Utama

b. Tampilan List Akomodasi

Berikut tampilan menu List Akomodasi setelah user melakukan proses input parameter. Sistem menampilkan daftar akomodasi sesuai dengan parameter yang dipilih user.

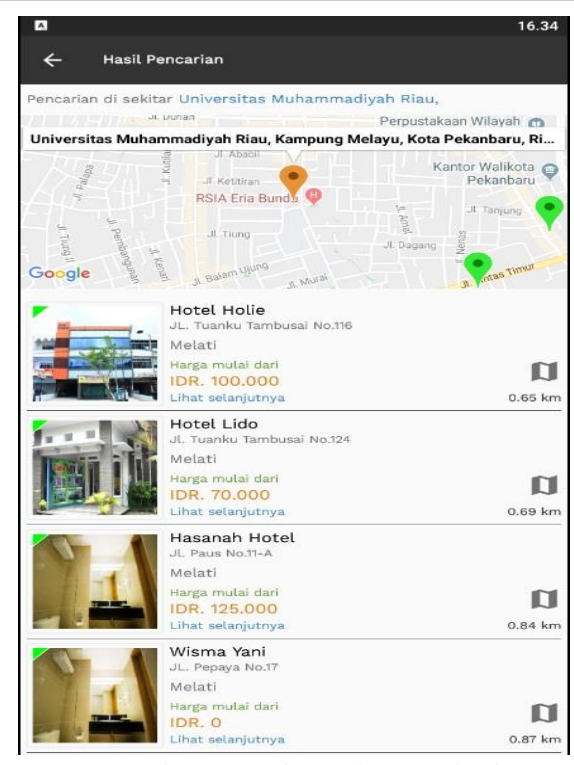

Gambar 7. List Akomodasi

c. Tampilan Menu Detail Akomodasi

Berikut merupakan tampilan halaman detail akomodasi pada user yang ditampilkan oleh sistem setelah user memilih akomodasi pada daftar. Selain itu sistem memberikan informasi pariwisata dengan jarak maksimal $6 \mathrm{~km}$ disekitaran akomodasi.
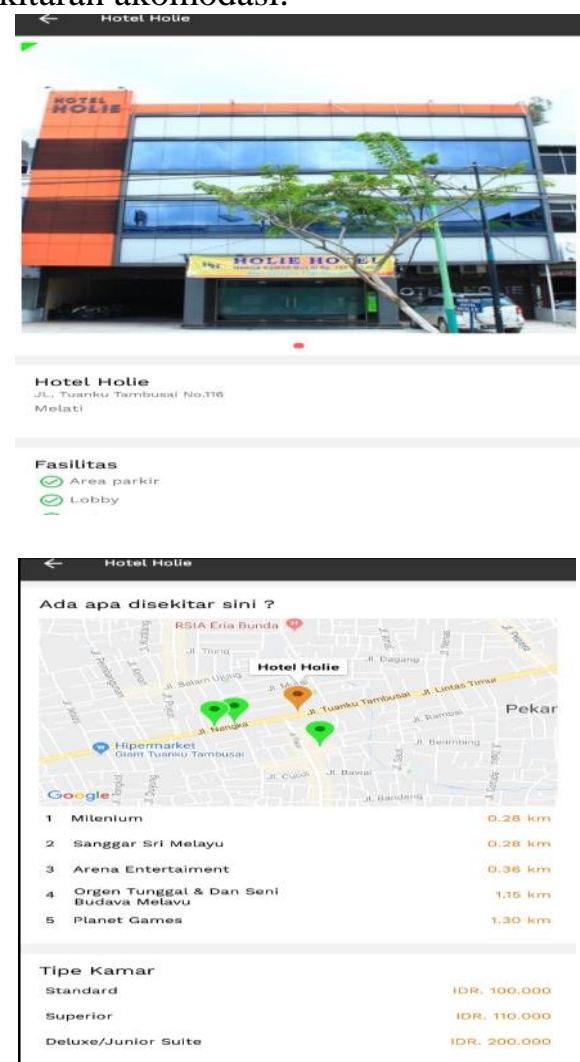

Gambar 8. Menu Detail Akomodasi

d. Detail Informasi Pariwisata 
Berikut merupakan tampilan halaman detail informasi pariwisata pada user yang ditampilkan oleh sistem setelah user memilih pariwisata. Sistem menampilkan detail informasi pariwisata yaitu nama tempat pariwisata, gambar, alamat, keterangan dan peta.

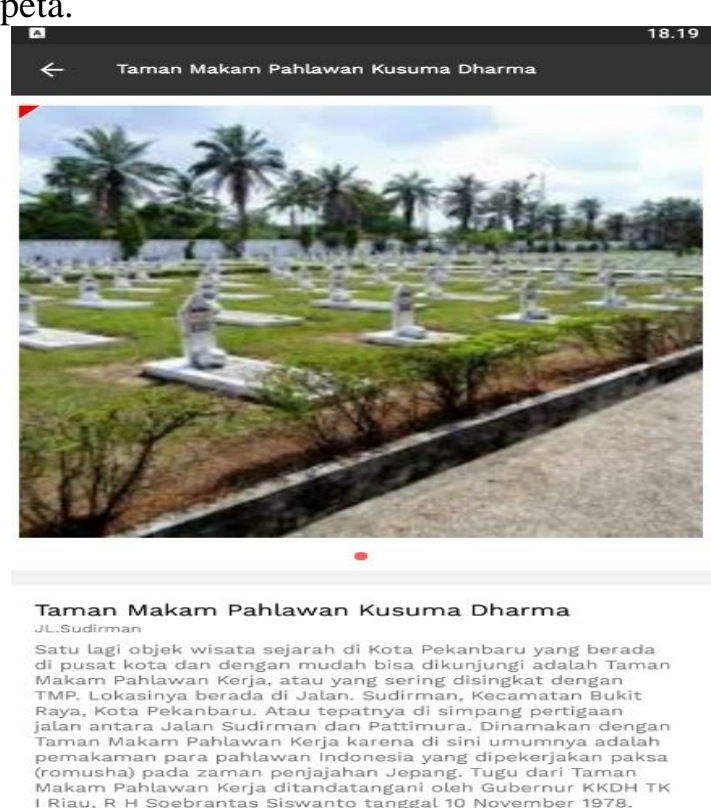

Gambar 8. Detail Pariwisata

Pengujian Sistem

Pengujian dilakukan untuk mengetahui dan mengukur apakah sistem yang telah dibuat dapat berjalan sesuai dengan tujuan. Pengujian pada penelitian ini menggunakan metode black box testing.

Tabel 2. Tabel Pengujian

\begin{tabular}{|c|c|c|c|c|}
\hline \multicolumn{5}{|c|}{ Sisi Pengguna } \\
\hline No & Use Case & $\begin{array}{c}\text { Jenis } \\
\text { Pengujian }\end{array}$ & $\begin{array}{c}\text { Kode } \\
\text { Penguj } \\
\text { ian }\end{array}$ & Status \\
\hline 1 & $\begin{array}{l}\text { Tampilan } \\
\text { Inputan } \\
\text { Parameter }\end{array}$ & Black box & $\begin{array}{c}\text { Uji - } \\
01\end{array}$ & Berhasil \\
\hline 2 & $\begin{array}{c}\text { Tampilan } \\
\text { Detail } \\
\text { Akomodasi } \\
\text { Berdasarkan } \\
\text { Parameter } \\
\end{array}$ & Black box & $\begin{array}{c}\text { Uji- } \\
02\end{array}$ & Berhasil \\
\hline 3 & $\begin{array}{c}\text { Rekomendasi } \\
\text { Pariwisata }\end{array}$ & Black box & $\begin{array}{l}\text { Uji- } \\
03\end{array}$ & Berhasil \\
\hline 4 & Map & Black box & $\begin{array}{c}\text { Uji- } \\
04 \\
\end{array}$ & Berhasil \\
\hline \multicolumn{5}{|c|}{ Sisi Admin } \\
\hline 5 & Login & Black box & $\begin{array}{c}\text { Uji - } \\
05\end{array}$ & Berhasil \\
\hline
\end{tabular}

\begin{tabular}{|c|c|c|c|c|}
\hline \multicolumn{5}{|c|}{ Sisi Admin } \\
\hline $\begin{array}{l}\mathrm{N} \\
\mathrm{O}\end{array}$ & Use Case & $\begin{array}{c}\text { Jenis } \\
\text { Pengujian }\end{array}$ & $\begin{array}{c}\text { Kode } \\
\text { Pengujian }\end{array}$ & Status \\
\hline 6 & $\begin{array}{c}\text { Kelola } \\
\text { Akomodasi }\end{array}$ & Black box & $\mathrm{Uji}-06$ & $\begin{array}{c}\text { Berhasi } \\
\quad l\end{array}$ \\
\hline 7 & $\begin{array}{l}\text { Kelola Tipe } \\
\text { Akomodasi }\end{array}$ & Black box & Uji -07 & $\begin{array}{c}\text { Berhasi } \\
\quad l\end{array}$ \\
\hline 8 & $\begin{array}{c}\text { Kelola Tipe } \\
\text { Kamar }\end{array}$ & Black box & $\mathrm{Uji}-08$ & $\begin{array}{c}\text { Berhasi } \\
\quad l\end{array}$ \\
\hline 9 & $\begin{array}{l}\text { Kelola } \\
\text { Wisata }\end{array}$ & Black box & Uji -09 & $\begin{array}{c}\text { Berhasi } \\
\quad l\end{array}$ \\
\hline 10 & $\begin{array}{c}\text { Kelola Tipe } \\
\text { Wisata }\end{array}$ & Black box & $\mathrm{Uji}-10$ & $\begin{array}{c}\text { Berhasi } \\
\quad l\end{array}$ \\
\hline 11 & $\begin{array}{c}\text { Kelola } \\
\text { Fasilitas }\end{array}$ & Black box & $\mathrm{Uji}-11$ & $\begin{array}{c}\text { Berhasi } \\
l\end{array}$ \\
\hline
\end{tabular}

Berdasarkan hasil pengujian aplikasi Rekomendasi Akomodasi dan Informasi Pariwisata yang mengacu pada pengujian kasus menggunakan metode black box testing, maka didapat kesimpulan tidak terdapat kesalahan proses dan secara fungsional sudah berjalan sesuai dengan yang diharapkan.

\section{SIMPULAN DAN SARAN}

Kesimpulan yang didapat dari pembuatan aplikasi rekomendasi akomodasi dan informasi pariwisata berbasis android adalah sebagai berikut :

a. Telah dibangun sebuah aplikasi rekomendasi akomodasi dan informasi pariwisata di Kota Pekanbaru berbasis android.

b. Aplikasi ini dapat digunakan untuk membantu pengguna dalam mencari lokasi akomodasi yang dekat dengan lokasi tujuan pengguna serta tempat penginapan yang sesuai dengan kebutuhan pengguna. Selain itu, aplikasi ini membantu dalam memberikan informasi pariwisata disekitaran akomodasi.

Dari pembuatan aplikasi rekomendasi akomodasi dan informasi pariwisata berbasis android, berikut ini ada beberapa saran yang mungkin dapat menjadi bahan pertimbangan dalam upaya meningkatkan kualitas sistem dimasa yang akan datang diantaranya yaitu,

a. Perlu adanya pengembangan pada desain tampilan agar lebih menarik.

b. Penelitian selanjutnya perlu ditambahkan atau dikembangkan dalam melakukan reservasi/ booking akomodasi.

\section{DAFTAR PUSTAKA}

[1] Agus Adhi Sumitro et.al, 2017. Implementasi Location Based Service untuk Aplikasi Mobile City Directory Studi Kasus Kota Kotamobagu. EJournal Teknik Informatika, ISSN: 2301-8364 Volume 11.

[2] Andi Juansyah, 2015. Pembangunan 
Aplikasi Child Tracker Berbasis Assisted - Global Positioning System (A-Gps) Dengan Platform Android. Jurnal Ilmiah Komputer dan Informatika (KOMPUTA), ISSN: 20899033 Volume 1, No.1 Agustus 2015.

[3] Anisah Budiwati, 2016. Tongkat Istiwa', Global Positioning System (GPS) dan Google Earth Untuk Menentukan Titik Koordinat Bumi dan Aplikasinya Dalam Penentuan Arah Kiblat. Al-Ahkam, ISSN: 0854-4603 Volume 26, No.1 April 2016.

[4] Assaf Arief et.al, 2012. Rancang Bangun Sistem Rekomendasi Pariwisata Mobile dengan Menggunakan Metode Collaborative Filtering dan Location Based Filtering. Jnteti, ISSN: 2301 - 4156 Volume 1, No.3 November 2012.

[5] Badrul Anwar et.al, 2014. Implementasi Locations Based Service Berbasis Android untuk Mengetahui Posisi User. Jurnal SAINTIKOM, ISSN: 1978-6603 Volume 13, No.2 Mei 2014.

[6] Defni dan Indri Rahmayun, 2014. Enkripsi SMS ( Short Message Service ) Pada Telepon Selular Berbasis Android Dengan Metode RC6. Jurnal Momentum, ISSN: 1693-752X Volume 16, No.1 Februari 2014.

[7] Dyas Larasati dan Muzayin Nazaruddin, 2016. Potensi Wisata Dalam Pembentukan City Branding Kota Pekanbaru. Jurnal Komunikasi, ISSN: 1907-898X Volume 10, No.2 April 2016.

[8] Ely Setyo Astuti et.al, 2015. Sistem Informasi Geografis Sistem Informasi Pencarian dan Navigasi Lokasi Wisata Bersejarah Kota Malang Berbasis Android. SEMNASKIT, ISSN: $2477-$ 5649.

[9] Faizal Ari Prabowo dan Mamay Syani, 2017. Sistem Informasi Pengolahan Sertifikat Berbasis Web Di Divisi Training Seamolec. Jurnal Masyarakat Informatika Indonesia, ISSN: 25415093 Volume 2, No.1 Januari - Maret 2017.

[10] Indra Permana et.al, 2015. Location Based Service sebagai Penunjuk Lokasi Hotel di Kota Semarang Berbasis
Augmented Reality," Jurnal Teknologi dan Sistem Komputer, ISSN: 23380403 Volume 3, No.4 Oktober 2015. 